\title{
AC 2011-2080: ENGAGING STUDENTS IN STEM EDUCATION THROUGH A VIRTUAL LEARNING LAB
}

\author{
Stephanie Elizabeth August, Loyola Marymount University
}

Stephanie August is an Associate Professor and Director of Graduate Studies in the Department of Electrical Engineering and Computer Science at Loyola Marymount University, Los Angeles. She teaches courses in artificial intelligence, database management systems, and software engineering. Her research interests include cognitive science applications of artificial intelligence including interdisciplinary new media applications, natural language understanding, argumentation, and analogical reasoning. She has several publications in these areas. Dr. August is actively involved in the Scholarship of Teaching and Learning community and is a 2006 CASTL Institute Scholar (Carnegie Academy for the Scholarship of Teaching and Learning). She has published a case study to use in teaching computer science courses to increase the interpersonal orientation of the classroom experience. She is currently directing graduate and undergraduate students on NSF-funded projects to develop a Virtual Engineering Sciences Learning Lab in Second Life to provide an immersive learning environment for introductory engineering and computer science courses and to develop materials for teaching artificial intelligence through an experimental approach modeled after the lab sciences. Her industry experience includes software and system engineering for several defense C3I programs, and applied artificial intelligence research for military and medical applications.

\section{Allison Neyer, Department of Electrical Engineering and Computer Science}

VESLL (Virtual Engineering Sciences Learning Lab) is an online virtual learning environment and interactive museum that uses games and activities to explain basic math and science concepts. I'm Allison Neyer, a senior English major with a computer science minor. As a research assistant on the VESSL project, I created and programmed the crossword and jumble puzzle activities as one part of this overall project.

\section{Don Brian Murphy, Loyola Marymount University}

Don Murphy is a graduate of Loyola Marymount University with a bachelor's degree in computer science. He has contributed to the XMLPipeDB program suite, the social networking site Serengeti, and the Virtual Engineering Science Learning Lab (VESLL) project. He worked in the university's computer science lab as a teacher's assistant, and has experience with programming languages including Java and C++.

\section{Robert Quinlan Thames}




\title{
Engaging Students in STEM Education through a Virtual Learning Lab Stephanie E. August* Michele Hammers** Allison Neyer* Daryoush Shokrgozar* Don Murphy* Robert Q. Thames* James Vales* \\ *Department of Electrical Engineering and Computer Science ** Department of Communication Studies Loyola Marymount University 1 LMU Drive \\ Los Angeles, CA 90045-2659 \\ 310-338-5973 \\ saugust@1mu.edu mhammers@1mu.edu waterrose9@aol.com dshokrgo@lion.lmu.edu dmurph21@lion.lmu.edu rqthames@yahoo.com jamesvales226@gmail.com
}

\begin{abstract}
Rather than waiting for students to pursue STEM education, virtual worlds and games can be used to bring science, technology, engineering, and mathematics to the students through engaging and socially oriented activities. We are developing a virtual science museum and education center that provides virtual practice with basic engineering concepts and transforms an entertainment-based platform into a delivery vehicle for electrical engineering and computer science content. This approach offers students autonomy and immediate feedback, and is designed to attract diverse audiences to engineering and computer science. This paper reports preliminary results of this research study.
\end{abstract}

\section{Overview}

The NSF Cyberlearning initiative calls for engineering educators to respond to the compelling need for improved competitiveness in engineering-related fields. ${ }^{1,2,3}$ A particular challenge is to attract an adequately deep pool of diverse, multi-talented individuals who are interested in the study and practice of engineering in socially-aware and collaborative contexts. ${ }^{4}$ These engineers will need both disciplinary expertise and the communicative and small-group collaboration skills necessary to work in diverse teams. ${ }^{1,4,5}$ The Virtual Engineering Sciences Learning Lab ${ }^{A} 6$ (VESLL) is answering this challenge. This project introduces a social element to the learning experience and incorporates activities that provide the satisfaction of accomplishment we often associate with game playing.

This paper describes the nature of this project, presents preliminary results, and discusses the opportunities it presents for interdisciplinary collaboration. We conclude with a look at how this approach facilitates interdisciplinary studies and present future plans.

$\grave{A}$ This material is based upon work supported by the National Science Foundation under Innovations in Engineering Education, Curriculum, and Infrastructure (IEECI) Grant No. 093510. Any opinions, findings and conclusions or recommendations expressed in this material are those of the author(s) and do not necessarily reflect the views of the National Science Foundation (NSF). 


\section{VESLL: Virtual Enginee ring Experience}

VESLL is establishing an online interactive learning environment designed to introduce students to engineering concepts through visualization and collaborative problem solving. Our long-term vision is to create a virtual version of a science museum such as the Exploratorium in San Francisco, the Pacific Science Center in Seattle, or the California Science Center in Los Angeles that provides virtual visitors the opportunity to delve into engineering concepts and maintain a sense of excitement about the concepts they experience.

For this project we have co-opted the immensely popular ${ }^{7}$ entertainment-based platform of Second Life, a virtual world in which users explore regions, meet and socialize with other users and participate in a broad spectrum of activities that reflect everyday real-world activities. This medium provides an opportunity to bring education to people where they play and embed it in their virtual experiences in a seamless fashion. This approach allows us to exploit entertainmentdeveloped tools while exploring their limits, addressing such questions as how to best co-opt these tools for education and how to create automated tutors or docents to guide visitors through educational activities.

VESLL enhances student learning via multi-modal pedagogical strategies while increasing engagement via its welcoming, dynamic environment, designed to be conducive to women and other diverse audiences. As part of an initiative to move engineering education into the $21^{\text {st }}$ Century, VESLL represents an exploration of the many benefits of virtual learning environments, including: enhanced opportunities for visualization, immediate feedback, student autonomy, increased access to resources without the demands of co-presence, multiple communication channels for student interaction with peers and instructors, and innovative ways to evaluate student learning.

Located on an "island" in Second Life, VESLL includes an orientation center, virtual meeting areas, and interactive exhibits, along with the virtual lab itself where students will learn about and experiment with fundamental engineering concepts, starting with logic concepts (AND, OR, NOT, XOR), gates, circuits, and number systems then progress on to more advanced problem solving. Figure 1 depicts avatars visiting interactive exhibits for logic operations and binary and hexadecimal number representations and conversions. These exhibits are part of a multi-modal scaffolding that teaches logic operations, number conversions, and logic gates. After students are introduced to a topic using traditional lecture methods, they retrieve assignments and access tutorials through their avatars, carry out experiments and activities using scripted objects, then complete assessments, all on Engineering Island in Second Life. Just as a real-life museum has guides to assist with and monitor visitor interactions with exhibits, we are developing automated docents to direct visitors to the educational activities on Engineering Island.

The social aspect of engineering is featured in the activities we create on the island. VESLL incorporates both indoor and outdoor virtual workspaces for performing experiments and various activities as well as a socializing/humanizing (S/HE) cafe where an avatar can meet other avatars to discuss problems or participate in discussions, lecture, presentations or other activities. The $\mathrm{S} / \mathrm{HE}$ Café will be patterned after the gathering places often incorporated into Women in Science 
and Engineering support programs. The virtual walls will include posters proclaiming the accomplishments of female and male engineers in equal numbers and focus on accomplishments related to solving social problems. Figure 2 shows avatars visiting displays in the café. Future plans include developing a sculpture garden with engineering exhibits to display accomplishments such as the engineering of pumps that bring water to remote villages, sensors that control flooding in a community, or satellite technology that enables people in remote regions to maintain contact with medical professionals in urban areas.

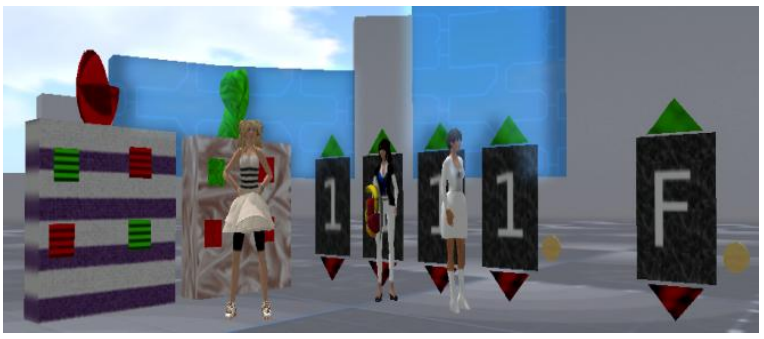

Figure 1. Virtual logic and conversion activities.

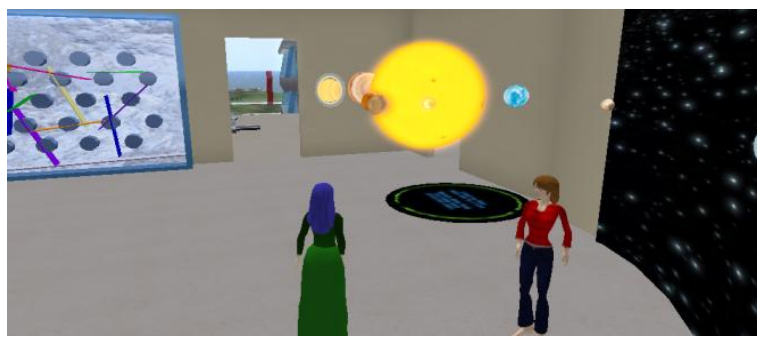

Figure 2. Avatars enjoying the Rube Goldberg machine and solar system exhibits in the S/HE Café on Engineering Island

VESLL has the potential to broaden the participation of underrepresented groups in STEM education. Because it provides expanded access to innovative STEM education learning tools, VESLL can be used to recruit K-12 students from underrepresented groups into STEM educational fields. For example, early research suggests that MUVE-based learning resources can be designed to be equally appealing to both male and female learners 8 thus VESLL has the potential to help recruit and retain young women as well as young men. We have developed activities to engage students learning about positional numbering systems, logical operations, logic gates, and simple circuits. Table 1 lists the interactive artifacts currently available along with their related educational goals and learning objectives. Students can experience the activities either in the context of an instructor led-workshop or on an individual basis. Here we describe these activities as they are presented in a VESLL workshop.

\section{A VESLL Workshop}

In a typical VESLL workshop, the instructor provides each student or pair of students with one of our pre-existing visitor avatars or visitars to access LMU Engineering Island in Second Life and the custom-made course content featured in the workshop. Each visitar is named after a famous scientist, engineer, or inventor. The instructor explains the virtual environment and gives a brief introduction to maneuvering the avatars. Students are also given a guided tour by sitting their visitars on an automated tram which then travels around Engineering Island making predefined stops to tell the visitors about the sites and activities available. For each activity, the visitars are guided to a virtual classroom for a brief lecture "in world" on a specific topic and a demonstration of the related activity, after which they move to the virtual workshop where students work in pairs to complete exercises related to the topic using the interactive exhibits. 
Table 1. VESLL interactive artifacts.

\begin{tabular}{|l|l|l|}
\hline \multicolumn{1}{|c|}{ Artifact } & \multicolumn{1}{|c|}{ Educational Goal } & \multicolumn{1}{c|}{ Learning Objective } \\
\hline $\begin{array}{l}\text { Set of panels to represent and } \\
\text { numbers in multiple bases and } \\
\text { demonstrate counting in each base. }\end{array}$ & $\begin{array}{l}\text { Learn positional number } \\
\text { systems and conversions. }\end{array}$ & $\begin{array}{l}\text { Students will demonstrate ability } \\
\text { to represent numbers in binary, } \\
\text { decimal, and hexadecimal; to } \\
\text { convert numbers among binary, } \\
\text { octal, decimal, and hexadecimal } \\
\text { alphabetical characters in the } \\
\text { hexadecimal numbering system. } \\
\begin{array}{l}\text { Word Jumble, utilizing the } \\
\text { alphabetical characters in the } \\
\text { hexadecimal numbering system. } \\
\text { various number systems. }\end{array}\end{array}$ \\
\hline $\begin{array}{l}\text { Basic logic boards, panels with input } \\
\text { buttons that students can toggle } \\
\text { on/off and a beacon to provide } \\
\text { feedback to check an answer. Each } \\
\text { board represents an expression that } \\
\text { uses a single logical operation. }\end{array}$ & $\begin{array}{l}\text { Learn basic logical } \\
\text { operations AND, OR, XOR } \\
\text { and NOT. }\end{array}$ & $\begin{array}{l}\text { Students will demonstrate recall } \\
\text { and general understanding of } \\
\text { basic logic operations AND, OR, } \\
\text { XOR and NOT. }\end{array}$ \\
\hline $\begin{array}{l}\text { Interactive logic posters } \text { or boards } \\
\text { and predefined circuits. }\end{array}$ & $\begin{array}{l}\text { Learn basic logical } \\
\text { operations AND, OR, XOR } \\
\text { and NOT and the operation } \\
\text { of corresponding logic } \\
\text { gates. }\end{array}$ & $\begin{array}{l}\text { Students will be able to interpret } \\
\text { a truth table and predict the } \\
\text { response of individual AND, OR, } \\
\text { XOR and NOT gates, a FLIP FLOP, } \\
\text { and other simple circuits to a } \\
\text { variety of input. }\end{array}$ \\
\hline $\begin{array}{l}\text { Logic gate dispenser, panel with } \\
\text { components that can be used to } \\
\text { create a circuit. }\end{array}$ & $\begin{array}{l}\text { Learn basic logical } \\
\text { operations AND, OR, XOR } \\
\text { and NOT and the operation } \\
\text { of corresponding logic } \\
\text { gates. }\end{array}$ & $\begin{array}{l}\text { Students will demonstrate the } \\
\text { ability to construct a simple } \\
\text { circuit that provides a specified } \\
\text { function. }\end{array}$ \\
\hline
\end{tabular}

\section{Positional Numbering Systems}

Activities related to positional numbering systems include counting, number conversions, a crossword puzzle, and a word jumble. Students can compare and convert numbers represented in various bases, such as binary, decimal, and hexadecimal, using a set of number panels (the HexWindow) as shown in Figure 3. Using their visitar, the student can touch the display to change the number displayed. A student can use the HexWindow to count up and down, like an odometer, or to enter a number such as $1111111_{2}$, which the student then converts to a representation in another base, e.g., $\mathrm{FF}_{16}$. In addition to being able to check their work, the students are able to observe directly the results of carry and borrow operations as they increment and decrement the counter using buttons above and below the panels. 


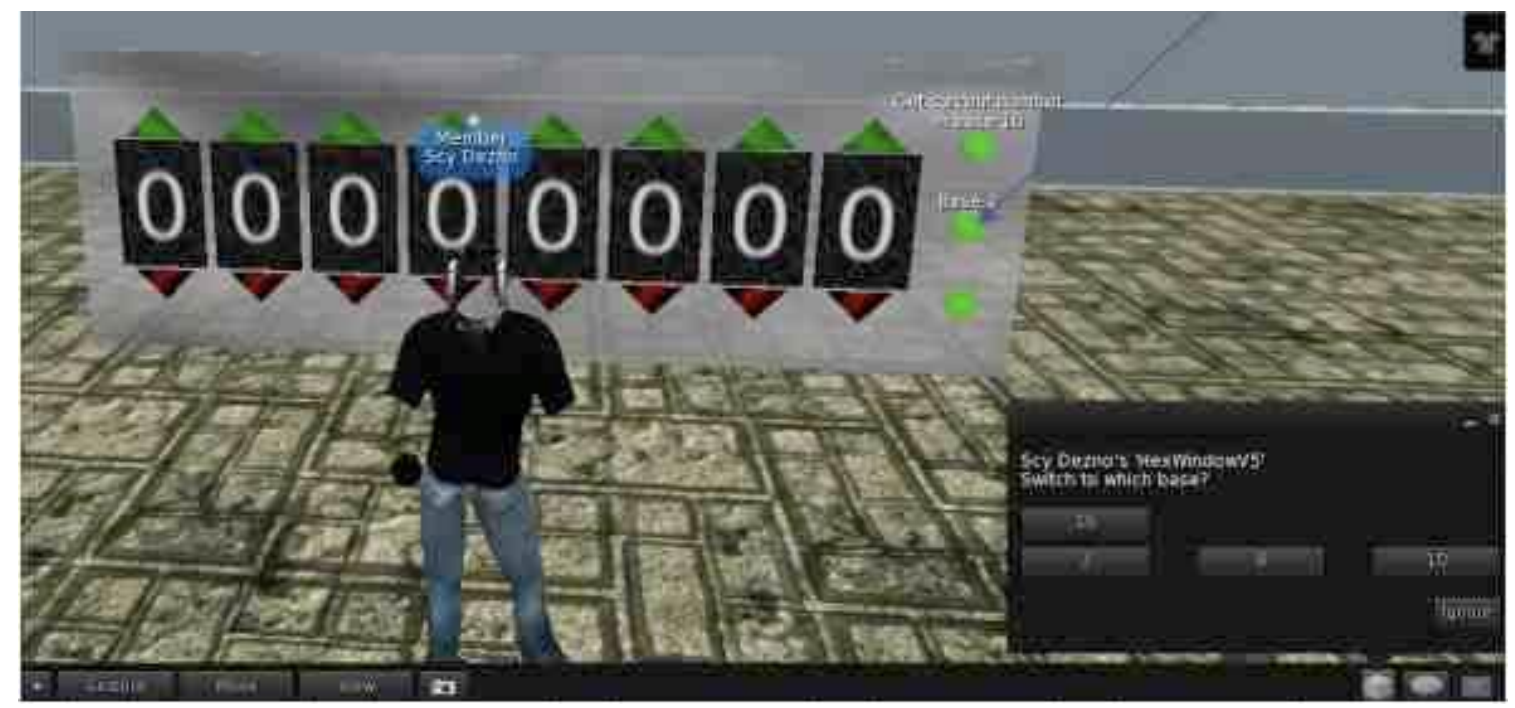

Figure 3. The HexWindow for learning positional numbering systems.

Buttons to the side of the panels allow students to switch between bases (converting the currently displayed value when possible), output the displayed value in base 10, and turn on and off carrying between number panels. After working with the HexWindow, students are directed to a Conversion Lock exercise, shown in Figure 4, whose functionality is similar to the HexWindow but designed to act much like a combination lock. To ñopenò the lock, students must convert a number provided with the lock to an equivalent number in a different base (specified by the lock) to obtain the correct combination. When the combination is entered, the lock opens and the students receive rewards, such as VESLL t-shirts for their visitars to wear.

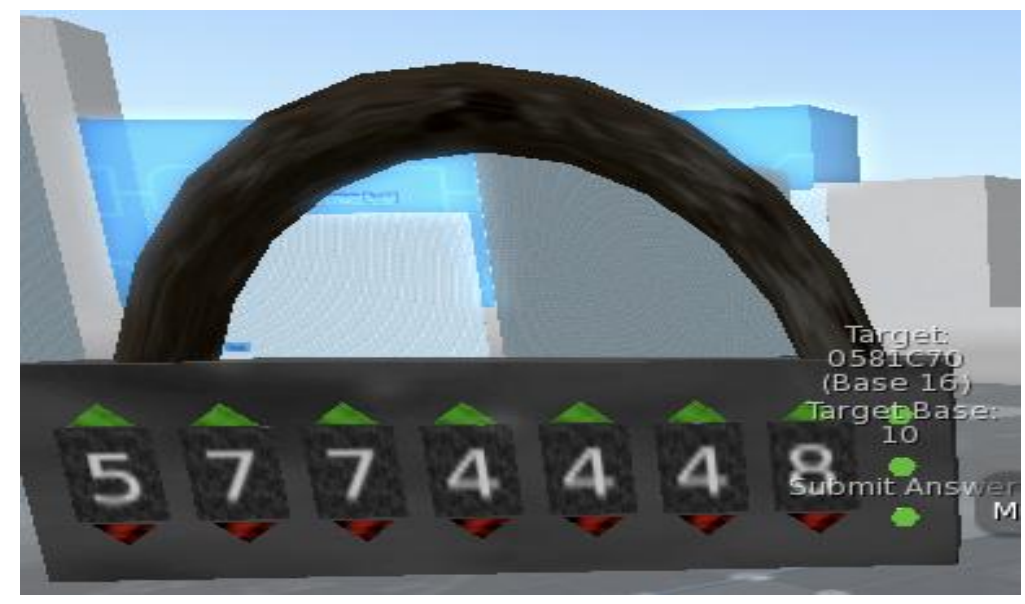

Figure 4. The Conversion Lock exercise.

We have created a crossword puzzle utilizing the number panels as an alternate exercise for practicing mathematical operations and conversions among various numbering systems. ${ }^{9}$ The visitar touches an instruction button associated with the puzzle to receive the clues for the puzzle. They enter their answers to the clues to solve the puzzle and can touch other buttons to check 
their answers or reset the puzzle, as shown in Figure 5. Figure 6 shows a word jumble activity that works in a similar fashion.

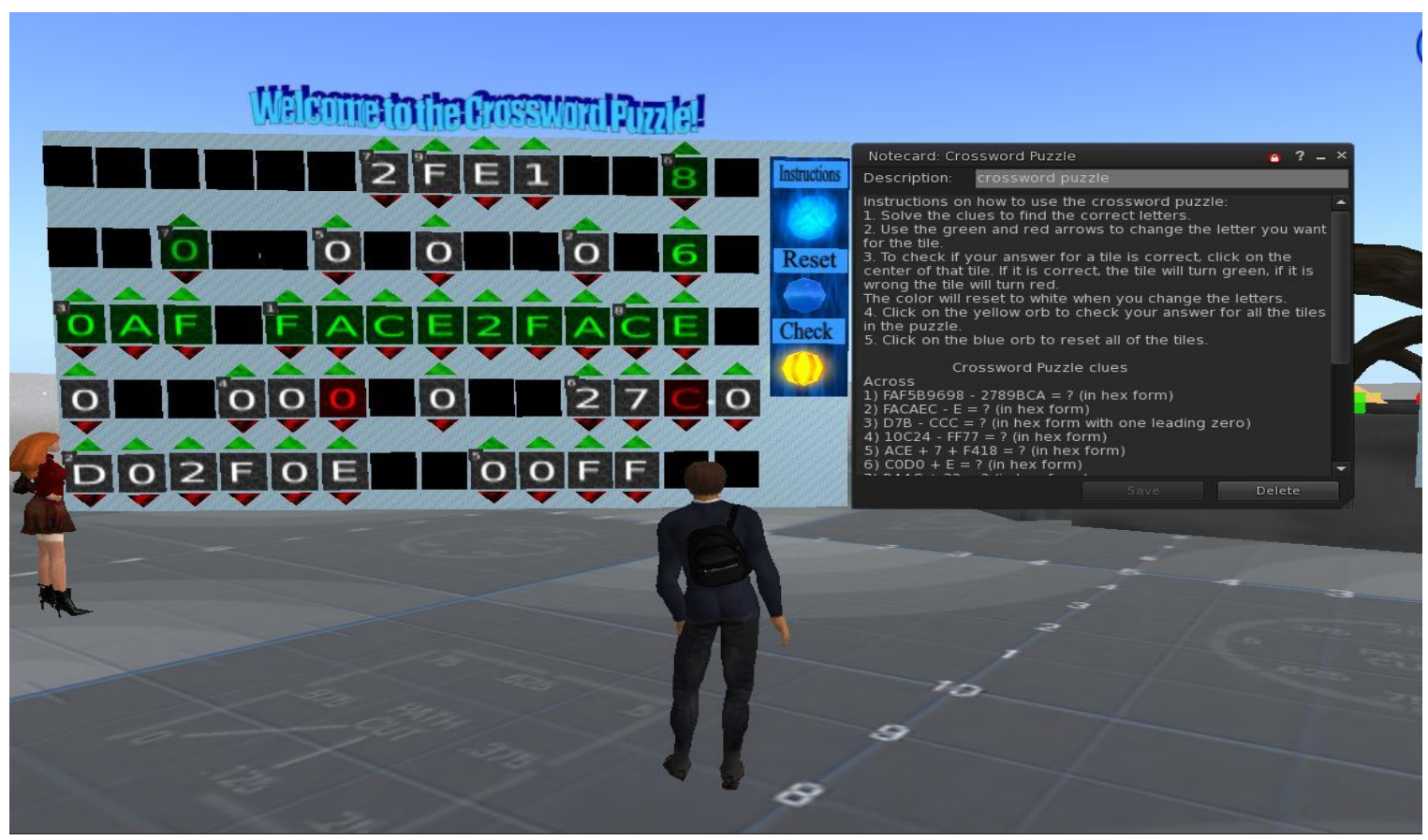

Figure 5. The Crossword Puzzle.

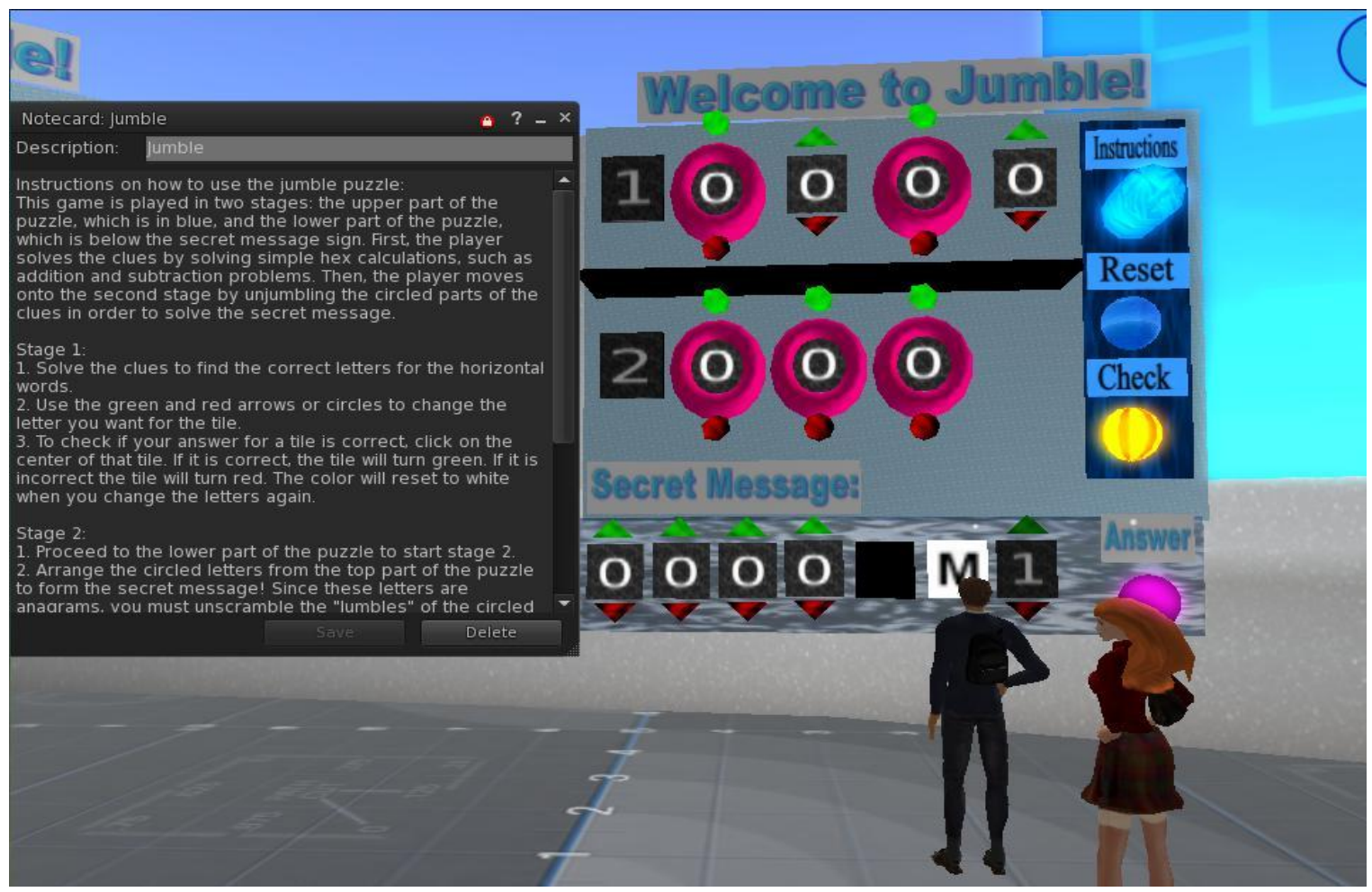

Figure 6. The Word Jumble. 


\section{Logic Circuit Lab}

Visitars entering the Logic Circuit Lab walk through a set of displays that define basic logic operations, truth tables, basic logic gates, and a flip flop. Students can observe the output of each gate as their visitars toggle the inputs on the sample gate available on a display board and on a pre-defined circuit. After walking through displays, students can build their own simple circuit using gates, inverters, and connectors taken from a "dispensing" board. To guide the activities, the visitars are given problems to solve along with guidelines for working with the circuits. Figure 7 shows the Logic Circuit classroom and demonstration station.

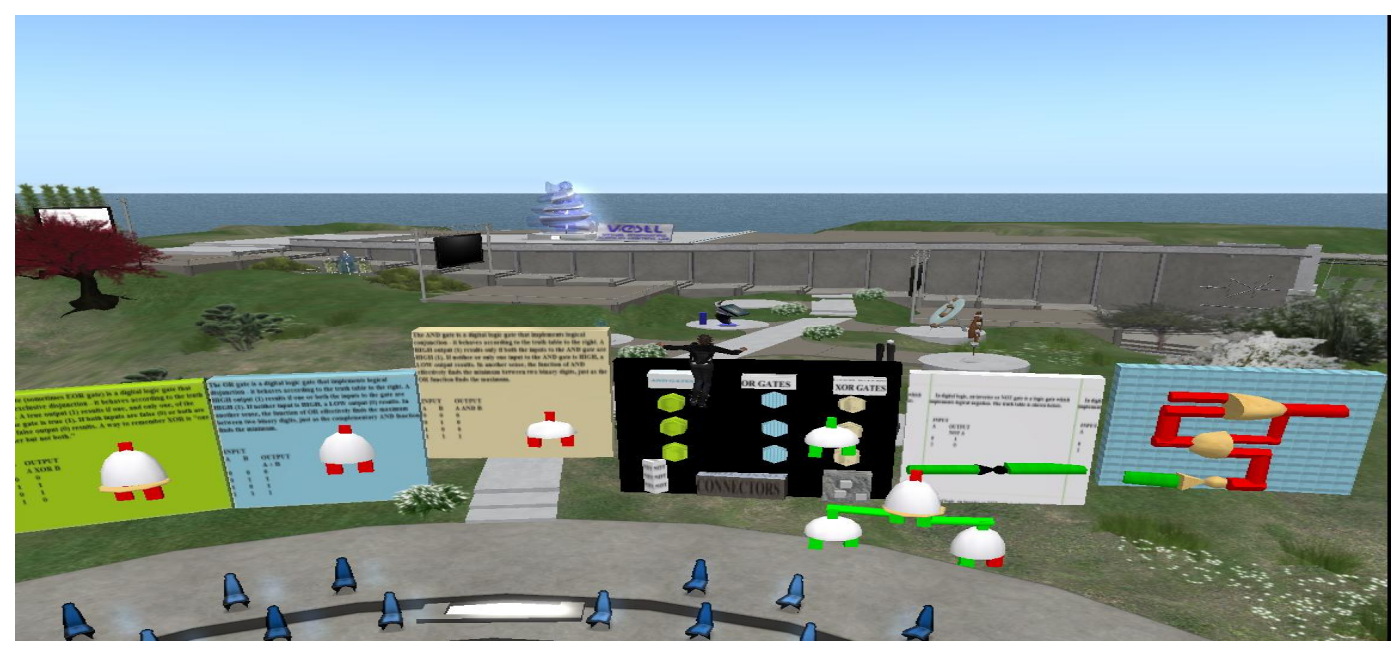

Figure 7. The Logic Circuit Lab with gates, circuit creation panel and predefined circuits.

\section{Results}

We have held one informal workshop for twelve students from our university who were enrolled in an Introduction to Computer Science course geared toward non-majors using a version of the HexWindow, and one formal workshop for eight students who are currently studying computer science, engineering, or mathematics at other colleges and universities using the set of activities outlined in Table 1. Data from these workshops is currently being analyzed. Preliminary feedback from the workshops is that the activities are related to course content, help students understand course content, and make course material more interesting.

Initial evaluation of the first set of assessment data from students in the informal workshop indicates that students found that working with the VESLL learning tools made the course material more interesting and encouraged interaction with other students; reporting on a five point Likert scale $(1=$ Strongly Disagree to $5=$ Strongly Agree $)$, the average score for increasing interest in the material was $3.83(\mathrm{n}=12)$ and the average score for encouraging interaction with other students was $3.42(\mathrm{n}=12)$. Because this assessment was conducted as part of an in-class workshop where a very early version of one learning object was previewed, we were encouraged by the positive responses to this early assessment. 
The formal assessment workshop yielded similarly positive results. Eight students (two females and six males) representing two community colleges and a University of California campus attended. During the workshop six different activities were tested and students were exposed to the basic functions of Second Life (notecard distribution, group chat, private chat, avatar movement, and object manipulation). Feedback from these students reporting on a five point Likert scale $(1=$ Strongly Disagree to $5=$ Strongly Agree $)$ was strongly positive on items such as:

. The workshop activities were interesting ways to learn the material. $($ mean $=4.71)$

. I enjoyed exploring the Second Life environment. $($ mean $=4.71)$

. Using Second Life made the learning experience more interesting than a regular classroom lecture. $($ mean $=4.71)$

. I would be likely to use learning activities of this kind as part of my studying/ preparation for class. $($ mean $=4.71)$

- Having access to activities like this online would make it easier to find time to work with classmates on assignments. $($ mean $=4.57)$

- These activities made me more interested in learning the material than I was before the workshop. $($ mean $=4.33)$

In addition to these overall assessments, each learning activity was assessed separately; these assessments also were generally positive. For example, in response to the statement ñThe activity helped me understand the content,ò responses for all activities fell in the 4.30 to 4.57 range. Preand post-knowledge assessments were administered at the formal workshop. Preliminary analysis of the results indicates that on average, students more than doubled their scores after working with the VESLL activities.

Additional feedback suggests that students need more time to familiarize themselves with object manipulation before attempting some in-world activities. Given the constructive feedback we received and the overall positive tenor of the results, we continue to be encouraged by our early assessment data.

Students participating in the first two workshops worked in pairs to complete the exercises. In the future, we want to increase the level of collaboration among the students. We are currently designing a scavenger hunt, which will involve the existing activities as well as the biographical information provided on displays throughout the island and other exhibits. We are also developing problems that will break into team-based subproblems; teams will solve their pieces independently then merge their solutions to solve the overall problem. As a trivial example, rather than having an individual or pair convert $\mathrm{ADE}_{16}$ to its decimal representation to open the Conversion Lock, individual teams would be given $\mathrm{AO}_{0} \mathrm{16}_{16}, \mathrm{D}_{16}$, and $\mathrm{E}_{16}$, respectively, to convert to decimal representations, after which the teams would need to combine their answers to open the lock. 
The more advanced students in the workshops expressed interest in more challenging activities. To address this and broaden the range of activities offered, we are developing a visualization of solving a differential equation using an integrating factor. A virtual and expandable tank of water with a changing concentration of a saline solution will allow users to adjust inputs to the tank and observe how volume and concentration change over time. This calculus problem will be integrated into the scavenger hunt along with the other activities.

The artifacts presented in this paper are streamlined and improved as students provide feedback on their use. Thus, their appearance on the island might differ from what is shown in this paper.

\section{Lessons Learned}

While the VESLL project is still in its development stages, the collaboration between teacherscholars from two different disciplines already has yielded insight. Two different collaborators with very different areas of expertise have come together to address the common problems of ñow do we help students visualize abstract content in ways that help them not only learn the material but also see the material as relevant to real-world problems? And what will motivate our students to approach potentially challenging material with an open-mind and optimism?ò We have learned that communicating across our own disciplinary boundaries requires careful attention to detail and vocabulary; we cannot assume that we understand each other just because we happen to be using the same words. We have learned that creativity fuels creativity and that crossing disciplinary boundaries can free us from the usual limits of what we consider acceptable answers to a problem; rather than starting by eliminating what we ordinarily could not do, we tend to begin by asking ñwhat would it look like if we could doé ?ò We have, in short, learned many of the lessons that we hope to share with our students.

The VESLL project has direct relevance to questions related to the long-term societal impacts of games and entertainment research. In fact, this project suggests that at least one long-term societal impact can be found amid the linkages between entertainment and education. Exploring enhanced interactions within an entertainment-based platform like Second Life directly ties game-based innovation into long-term educational goals.

The project can be visited by joining and logging into Second LifeÊ and searching for "LMU Engineering Island." The items described here are fully functional and available to anyone who visits the island.

\section{Acknowledgements}

The authors are especially grateful to Sukhanya Kethuneni, Penda Gueye, and Vaishali Varshney for their work on creating and reviewing the interactive objects in Second Life, and Chiquitta Johnson for her continuing support of the VESLL project. 


\section{References}

[1] Committee on the Engineer of 2020. 2005. Educating the engineer of 2020: Adapting engineering education to the new century. Washington, D.C.: National Academies Press.

[2] Fostering learning in the networked world: The cyberlearning opportunity and challenge. A 21st century agenda for the National Science Foundation. 2008. Report of the NSF Task Force on Cyberlearning. National Science Board. NSB-08-204. www.nsf.gov/pubs/2008/nsf08204/nsf08204.pdf. Last viewed 4 March 2009.

[3] Vest, C. M. 2008. Context and challenge for twenty-first century engineering education. Journal of Engineering Education, 97:3, 235-240.

[4] Moving forward to improve engineering education. 2007. National Science Board. NSB-07-122. www.nsf.gov/pubs/2007/nsb07122/nsb07122.pdf.(last accessed 2 March 2009)

[5] Redish, E. F. and Smith, K. A. 2008. Looking beyond content: Skill development for engineers. Journal of Engineering Education, 97:3, 295-307.

[6] August, Stephanie E. and Hammers, Michele L. 2009. IEECI: Encouraging Diversity in Engineering through a Virtual Engineering Sciences Learning Lab. NSF Grant no.0935100.

[7] Second Life Research: Second Life Residents Statistics. 08 March 2007. http://secondliferesearch.blogspot.com/2007/03/second-life-residents-statistics.html (last accessed 1 June 2009).

[8] Moreno, R. and Mayer, R. 2007. Interactive multimodal learning environments, special issue on interactive learning environments: Contemporary issues and trends. EducationPsychology Review, 19, 309-326. DOI= 10.1007/s10648-007-9047-2

[9] Neyer, Allison; August, Stephanie E.; and Hammers, Michele. 2011. Working together: words and math. To appear in Journal of Computing Sciences in Colleges, 26:4. 